\title{
Designing Web-Based RIA Platform for English Advising and Interactive Learning
}

\author{
Ruhua WEI ${ }^{1, a}$ \\ ${ }^{1}$ Hechi University College of Foreign Languages, Yizhou 546300,China \\ aweiruhua@163.com
}

Keywords: RIA Platform; English Advising; Interactive Learning

\begin{abstract}
This research paper demonstrates our novel research on building a free Internet-base, multi-agent and long distance teaching environment for English learning. Web English teaching environments are few, and mostly they imply a fee. However, none of them considers the challenges the non-native English-speaking academic has to face. Here we will describe some of the design and implementation aspects of the system prototype, focusing especially on the evolutionary, adaptive features, and only marginally on the pedagogical issues involved.
\end{abstract}

\section{Introduction}

As distances constantly grow smaller and the Internet links more and more remote parts of the world, English gradually becomes the lingua franca for information exchange. Especially in the academic field, in research and development, where international cooperation is a must, English is used frequently. Academic English is International English. Therefore, one has to be able to understand a multitude of accents from all around the world to be able to function in now-a-days society. However, although accents are more or less variable, the spoken, but mostly, the written academic language has still its rules and etiquette. Academics usually know some English and have a more or less wide English vocabulary.

However, especially in Japan, but in other non-English speaking countries as well, there exists the phenomenon that, although a person can read academic papers in English, when it comes to writing a paper by oneself, or to make an academic presentation in English, serious problems appear. Therefore, we embed these necessary rules and etiquette in our teaching environment. The main aim of our system is to help academics exchange meaningful information with their peers, through a variety of information exchange ways: academic homepages, academic papers, academic presentations, etc. As far as we know, this type of English teaching system is new. Some English teaching environments on the Web appeared, but, as in [Aspera PrivaTeacher] or [English Learner], they have two main defects: they are not free, and/or they are not automatic, but based on real human teachers at the end of the line. Good on-line dictionaries(e.g., [Jeffrey], [Dictionary]) and several collections of English on-line books (e.g., [Bartleby]) exist, but those can only act as auxiliary helpers during the English learning process.

Our aim is to have a system capable to function autonomously, without human interference, as a virtual, long-distance classroom, embedding the necessary tutoring functions within a set of collaborating agents that will serve the student.

\section{Related Work}

Virtual environments in education and distance-learning systems are the recent trends in education worldwide. This trend is determined by the current spread of the Internet, as well as by a real demand for better, easy-to-access, and cheaper educational facilities. Therefore, universities everywhere respond to the academic demand for technological and pedagogical support in course preparation, by developing specialized software environments [Collis]. As bandwidths grow, the traditional text environments gradually switch to multimedia and Video-on-Demand (VOD) systems ([Tomek]). There exists lots of related problems. These problems could not be solved by traditional systems, 
mostly due to their lack of adaptability, or in other words, intelligence. In [Weiss], it is stated: "there is the need to endow these systems with the ability to adapt and learn, that is, to self-improve their future performance".

The objective of this research is to help learners achieve academic reading and writing ability. The course is intended for students whose starting English level is intermediate and upper-intermediate, who have some vocabulary of English, but not much practice in using it. The tutoring strategy used is to give the reader insight into his or her implicit or explicit learning strategies. The methodology applied is the communicative teaching approach, allowing communication and interaction between student and tutoring system, via agents. The interactive reading strategies applied and yet to apply include bottom-up theory, top-down theory, and schemata theory. The topics and stories used are mainly passages from textbooks, journals, reference works, conference proceedings, and academic papers, in other words, real-life academic products.

\section{Overview of RIA Technology}

RIA (Rich Internet Applications), it is a desktop application of interactive user experience and the traditional Web application deployment flexibility and cost analysis of network application, as its structure shown in figure 1. RIA by providing the customer technology carry compiled the client application (in the form of a file, use HTTP transmission) operating environment, the client application using asynchronous client/server architecture to connect the existing back-end application server, it is a safe, scalable, have good adaptability of new service-oriented model, this model driven by using the Web server, is a combination of voice, video and integrated communication technology, real-time dialogue makes rich Internet application (RIA) has the unprecedented online user experience. RIA concept includes two aspects, respectively is the abundance of data models and user interface is rich. The user interface can display and operation more complex embedded in the client's data model, it can be operation client computing and synchronized to send and receive data. The advantages of this model compared with the traditional HTML page is a program running on the client and the program was conducted, and the user interaction, more and less and server to interact. Balance the client and the server complex data model, can let you have more space to create a more efficient and more interactive web applications.

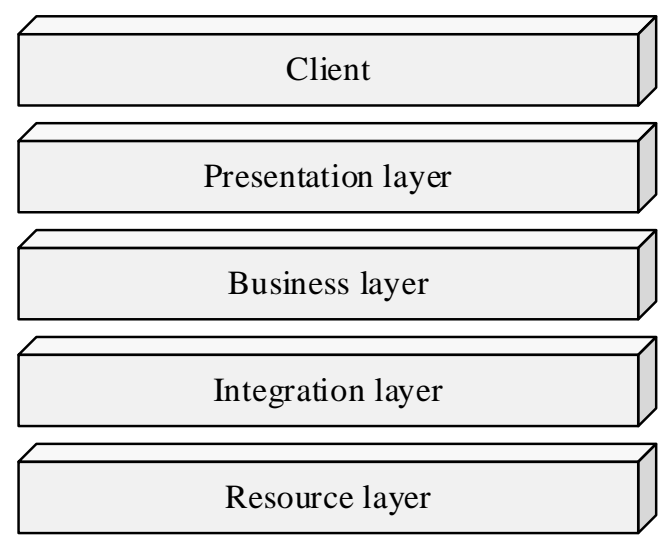

Figure. 1 The RIA structure model

RIA is the development of application system in the future, it is not only a revolution in business, in the field of education, RIA has broad prospects. This thanks to the widespread application of computer information technology in education, especially the introduction of some new teaching concept of flaring, such as: network education, computer assisted instruction and so on. So we can believe that RIA technology in our self-help learning platform can play its proper advantage, self-service learning platform can provide more help for learners. RIA let hair's aim is to solve the problem of user's experience, completely from the perspective of customers, to the user as the center, used in the education field, the show is centered on learners, for learners to enhance the function of 
interaction, improves the response time, the learners' interaction can make a rapid response, rich interface, data forms, both can create situation and can make students active participation, so can effectively stimulate students' interest in learning. RIA is a safe, scalable, and have good adaptability of new service-oriented model, this model is based on a Web server, it is a combination of voice, video, animation, exchange real-time newsletter, and other technology, can greatly enrich the learner's experience.

\section{Proposed System and Model}

General Features. The system is implemented as a multimedia environment for Academic Reading, Writing and Comprehension, allowing text, graphics, audio and video representation of the presented material. Programming and scripting languages used are CGI, Perl, Javascript and Java. Therefore, user browsers accessing it should, generally speaking, support these languages, HTML frames, and should install the free downloadable plug-in for audio and video presentation called 'Media Player'. The plug-ins for different environments are reachable from within the system environment, so the student-user overhead is kept low. The system can also be described with the following set of keywords: multimedia language learning system, AI-based knowledge extraction, interactive human machine communication system. Figure 2 shows the simplified system overview, represented as a set of interacting modules. The system offers two interfaces, one for the teacher/tutor user, for course-authoring purposes, and the other one for the student user, who is supposed to learn.

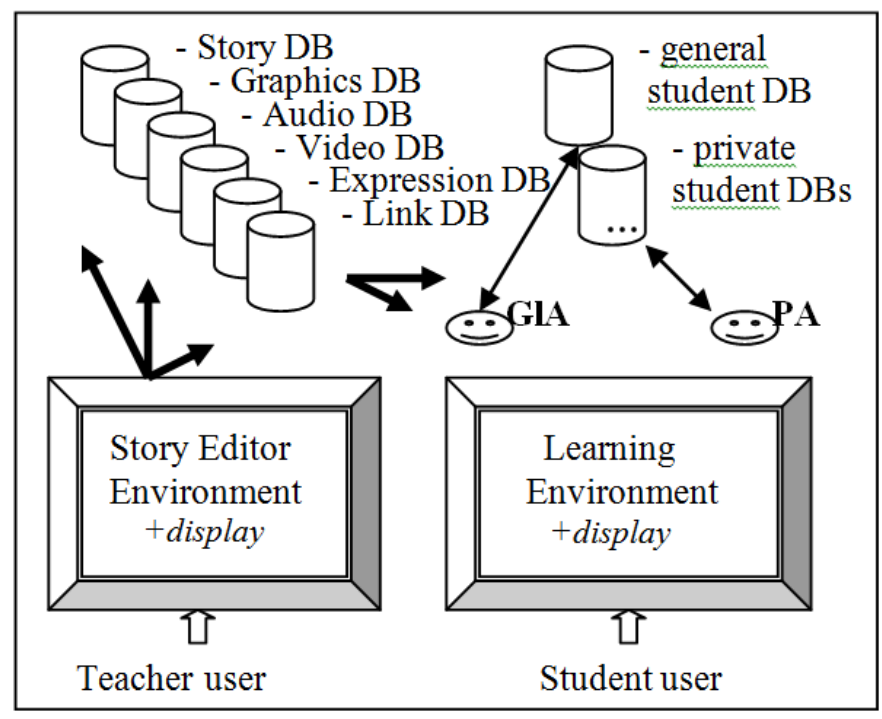

Figure. 2 The WSML System Framework

Authoring System Module. Our most important goal is to design a meaningful, evolutionary feedback for the user. In order to build such a system, an authoring tool is necessary for flexibility purposes: our colleagues researching the optimal material for academic English teaching should be able to add or delete freely the available resources. In a way, they are also clients/users, and should be restricted to build a courseware, which conforms to the capabilities of the system. In the following, these restrictions and their purposes are explained. These restrictions are necessary instruments for the two system agents to work with, as will be shown later in this paper. (1) Text: Each video/audio recording has to have a corresponding TEXT (of dialog, etc.). For each text, it is analyzed if video is necessary, or if audio suffices, as audio requires less memory space and allows a more compact storage and a speedy retrieval. Each TEXT also has (beside of main text, etc.), the following attributes: a short title, keywords, explanation, patterns to learn, conclusion, and finally, exercises. (2) Lessons: One or more TEXTs (with video or not) make up a LESSON. Each LESSON also has (beside of texts, etc.) the following attributes: title, keywords, explanation, conclusion, combined exercises (generated automatically or not). (3)Priority and Relatedness Connections: When 
introducing one or more subjects, the teacher has to specify the Priority Connections, i.e., to show the required learning order, with a directed graph (arrows). When there is no order, subjects will have the same priority, and build a set. The teacher (courseware author) should also add connections between related SUBJECTS, with indirect links. This means, the teacher has to add Relatedness Connections between subjects, for which no specific learning order is required, but which are related. These relations are useful, e.g., during tests: if one of the subjects is considered known, the other one should be also tested.

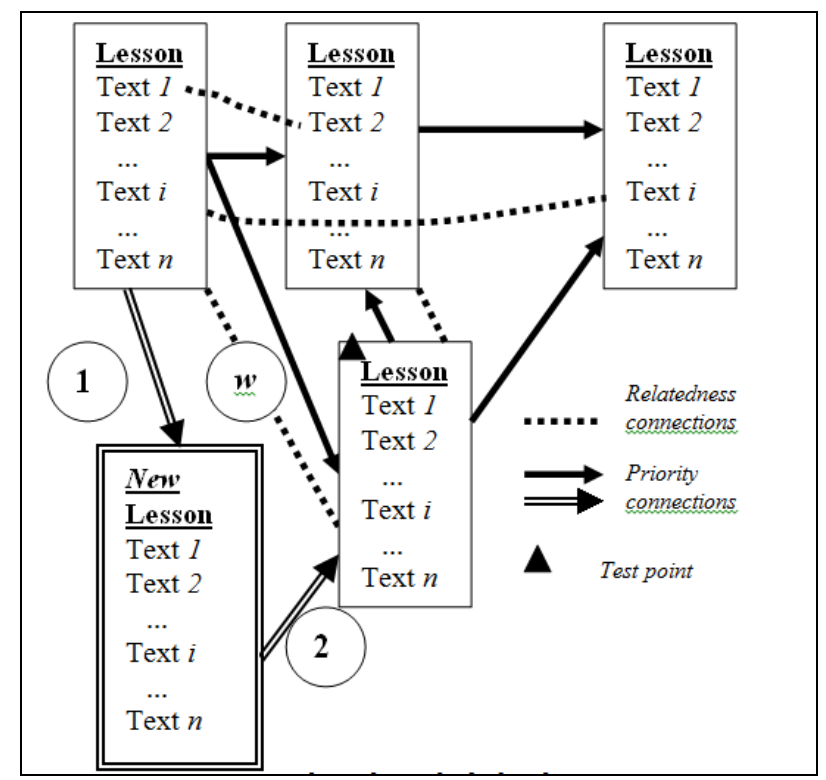

Figure. 3 The Subject Link Database

\section{Experimental Analysis}

The Learning Environment. The global agent averages information from several users, in order to obtain a general student model. The deductions of the global agent are bound to be non-specific. The GlA is necessary, because otherwise, the system will not profit from the fact that different users interacted with the system, and each new interaction can smoothen the path for following users. The GlA is to be referred before the PA starts looking for information from other PAs, process that can be more time-consuming. Therefore, the role of the GlA is to offer to the PAs condensed information, in an easily accessible, swiftly loadable form. As shown previously, the priority connections between lessons have no weight attached, but the relatedness connections have weights. These weights are changed interactively, as they reflect 'how connected' two subjects are. This information is useful for both guiding of the student during learning, as well as for testing the student. Weights' values are initialized as strong, when a teacher selects the respective links, and they are weaker, if the system (via the GlA) deduced them out of keyword search information (eq.1). The weights are changed by the GlA, according to the behavior of the students within the 'MyEnglishTeacher' environment (eq. 2).

$$
\begin{gathered}
w_{A, B}{ }^{0}=\{\mathbf{1} \text { : teacher selection; } \mathbf{0 . 5} \text { : system generation; } \mathbf{0} \text { : rest; }\} \\
\qquad w_{A, B}{ }^{t+t c o n s t}=a w_{A, B}{ }^{t}+\sum_{i=1}^{4} f(\mathrm{i})
\end{gathered}
$$

The Simulation. From the described interactions between agents and databases, and between the agents themselves, it is clear that the agents of the system work in two ways. The first way is based on the embedded rule/knowledge systems, which try to foresee, prevent and solve conflicting situations. The second way is as evolutionary, learning objects, which can adaptively change their representation of the subject space, by creating and deleting links and changing weights. A next step in the system's agents design will be focused on adaptive problem, quiz and test generation. In short, this design is 
made necessary by the fact that a student, after failing to pass a test, has to be presented, after some more learning is done, with a new test, of similar difficulty and contents. As it is difficult for the teachers to generate as many tests as would be necessary for such repeated situations, this task is to be passed to the system's agents. A very important task of each of the agents is also to keep the consistency of the subject link database. The agents inform the teacher(s) if some subjects form loops (determined by the priority connections set by the teacher(s)), if some subjects become inaccessible, etc. The following figure 4 is the computer-user interface.

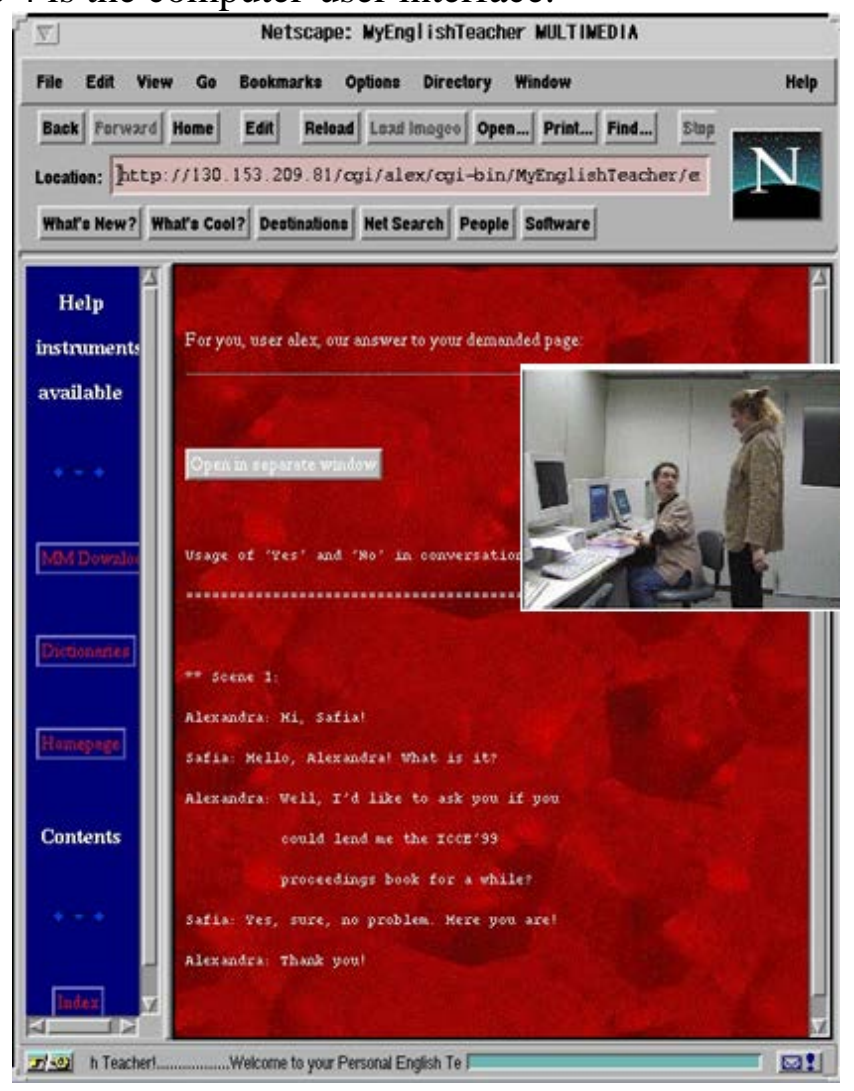

Figure.4 The Developed Platform

\section{Conclusion and Summary}

With the rapid development of network technology, especially in into the 21st century, the growth and dissemination of information data speed faster and faster. People understanding of network is more and more profound, also a big change study way. A college students just by handed out books from the school to study in the related professional knowledge is not enough, is not to meet the demand of the future development. Everyone should be independent to learn all kinds of professional related knowledge, self-study ability is good or bad determines whether a person is competitive, whether has huge potential, and is well acquainted in the information age to harness the power of knowledge. To build targeted autonomous learning, to meet the needs of information society for personal professional development, so establishing geared to the needs of the information age have intelligence, diversification of self-service learning platform is the foundation and key.

Traditional network learning platform based on the technology of HTML have been showing their technical shortcomings, unable to adapt to the learners more timely, more novelty experience requirements. And the emergence of RIA technology just for provides a good way to solve the problem.

We have proposed in this paper an Evolutionary, Web-based, Academic English Teaching Environment, called "My English Teacher". Moreover, we have described the rationale, the design and implementation of our system. Next, we have showed the modules, which the system should have, in order to function properly: an authoring environment for the teacher user(s), which is 
generating the lessons, and a learning environment for the student user(s). We have further on presented each of these modules in more details. In particular, the learning environment is based on two intelligent agents, interacting with each other and the student user, in order to guide the student through a new course for academic English, which is under development in our laboratory. We believe that with our system we are addressing more than one current need: the need of an English tutor for academics, which should also be easily accessible.

\section{References}

[1] Collins, A. and Michalski, R. (1989) “The logic of plausible reasoning: A core theory”, Cognitive Science, Vol. 13, 1-49.

[2] Chylinski R, Hanewald R. Creating supportive environments for CALL teacher autonomy[J]. Handbook of research on e-learning methodologies for language acquisition, 2012: 387-408.

[3] Ekdahl, B., Astor, E. and Davidsson, P. (1995) “Towards Anticipatory Agents”, Woolridge, M., Jennings, N.R. (Eds.), Theories, Architectures, and Languages, Lecture Notes in Artificial Intelligence, Springer Verlag, 191-202.

[4] Levy, M. (1997) “Computer-Assisted Language Learning”, Oxford Claredon Press.

[5] Maes, P. et al. (1993) "Learning Interface Agents", Proc. of the 11th Nat. Conf. On Artificial Intelligence, AAAI, MIT/AAAI Press.

[6] Gheorghe N. Interactive System For On-Line Consulting[J]. Annals of Faculty of Economics, 2009, 4(1): 1017-1020.

[7] EnglishLearner, http://www.Englishlearner.com 